\title{
Isolation of a SIR-like gene, SIR-T8, that is overexpressed in thyroid carcinoma cell lines and tissues
}

\author{
F de Nigris', J Cerutti' ${ }^{2}$ C Morelli ${ }^{3}$, D Califano', L Chiariotti ${ }^{4}$, G Viglietto ${ }^{1,2}$, G Santelli' and A Fusco*,2,4 \\ 'Senvizio di Oncologia Sperimentale 'E' Istituto per lo Studio e la Cura dei Tumori Fondazione 'G. Pascale', 80 I3I Napoli, Italy; ' Centro di Endocrinologia ed \\ Oncologia Sperimentale del CNR, clo Dipartimento di Biologia e Patologia Cellulare e Molecolare, Università di Napoli 'Federico Il', 80 I 3 I Napoli, Italy; \\ ${ }^{3}$ Kimmel Cancer Center, Jefferson Medical College, 2335 10th Street, Philadelphia, Pennsylvania, PA 19107, USA; ${ }^{4}$ Dipartimento di Medicina \\ Sperimentale e Clinica, Facoltà di Medicina e Chirurgia di Catanzaro, Università degli Studi di Catanzaro, 88I00 Catanzaro, Italy
}

We used subtractive library screening to identify the changes that occur in gene expression during thyroid cell neoplastic transformation. Complementary DNA from normal thyroid cells (HTC 2) was subtracted from a complementary DNA library constructed from a human thyroid papillary carcinoma cell line. The library was screened for genes upregulated in human thyroid papillary carcinoma cell line cells, and several cDNA clones were isolated. One of these clones has a sirtuin core and high homology with the human silent information regulator protein family. This clone, designated 'SIR-T8', was overexpressed in human thyroid carcinoma cell lines and tissues, but not in adenomas. The human SIR-T8 protein has a molecular weight of $39 \mathrm{kDa}$ and is primarily located in the cytoplasm under the nuclear membrane. The SIR-T8 gene is located on chromosome 17q25-1.

British Journal of Cancer (2002) 86, 917-923. DOI: 10.1038/sj/bjc/6600I56 www.bjcancer.com

(c) 2002 Cancer Research UK

Keywords: thyroid; neoplasias; expression; SIR2; telomerase

Malignant thyroid carcinomas deriving from follicular cells are relatively rare in humans. They are divided into differentiated tumours, which retain both structural and functional follicular cell differentiation, and undifferentiated tumours, in which evidence of differentiation is lacking. Undifferentiated carcinomas are rare, rapidly progressive tumours. Differentiated tumours, which form up to $90 \%$ of clinically detected thyroid carcinomas, are of two main types: papillary carcinomas and follicular carcinomas. This classification was originally based on the dominant architectural pattern of the tumour; it is now based on cytology, encapsulation, distribution of metastasis and molecular biology findings (Hedinger et al, 1989).

Studies from our laboratory and from other groups have helped to identify the molecular events involved in thyroid carcinogenesis, i.e., activation of the RET/PTC and of the TrkA tyrosine kinase receptors in papillary carcinomas, activation of the ras genes by point mutation and PPAR $\gamma$ inactivation by fusion with PAX 8 in follicular carcinomas (Kroll et al, 2000), and mutation of the p53 gene in anaplastic tumours (Pierotti et al, 1996; Fusco and Santoro, 1997). However, the mechanisms that regulate the process of transformation of thyroid cells remain largely unknown. The identification of genes regulated by cell transformation, e.g. c-myc (Cerutti et al, 1996), NF $\kappa \mathrm{B}$ p65 (Visconti et al, 1997), HMGI-C and HMGI (Y) (Chiappetta et al, 1995), galectin-1 (Chiariotti et al, 1993), thymosin $\beta$-10 (Califano et al, 1998), has also provided insight into the mechanisms regulating thyroid cell transformation.

\footnotetext{
*Correspondence: A Fusco; Dipartimento di Biologia e Patologia Cellulare e Molecolare, Facoltà di Medicina e Chirurgia di Napoli, Università degli Studi di Napoli 'Federico II', Via S Pansini 5, 80 I3I Naples, Italy; E-mail: afusco@napoli.com

Received 5 December 200I; accepted I4 December 200 I
}

In a previous screening of a subtractive complementary DNA (cDNA) library resulting from a human thyroid carcinoma and normal cell line, we identified the HIP gene, which is overexpressed in malignant thyroid neoplasias (de Nigris et al, 1998).

Here we report the isolation of a novel gene, designated 'SIR-T8' because of its strong homology with human sirtuin proteins and more in general with the silent information regulator (SIR) family of proteins. The SIR proteins encompass a large number of genes that have highly conserved structural homologous sequences in organisms ranging from bacteria to man (Brachman et al, 1995; Frye, 1999). Among them, the protein best characterised is SIR-2, which belongs to a multigene family (Brachman et al, 1995; Frye, 1999; Sherman et al, 1999) that has been implicated in silencing, chromosome stability, recombination (Brachman et al, 1995) and decreased rate of ageing (Kaeberlein et al, 1999). This gene attracted our attention because about $85 \%$ of all primary human cancers has telomerase activity (Kim et al, 1994; Shay and Bacchetti, 1997, Sprung et al, 1999). Attempts are underway to identify clinical situations in which telomerase has diagnostic or prognostic potential and to devise in situ techniques to distinguish telomerase produced by normal $v s$ cancer cells. Analysis of tumoral and normal thyroid tissues shows that the SIR-T8 gene is overexpressed in all differentiated and undifferentiated thyroid carcinomas cell lines and tissues examined. In contrast, its expression is weak or almost undetectable in all adenomas and normal thyroid tissues analysed.

\section{MATERIALS AND METHODS}

\section{Cell lines}

The human thyroid carcinoma cell lines (NIM1, TPC-1, NPA, WRO, ARO and FRO) are described elsewhere (Cerutti et al, 
1996). They were grown in DMEM plus $10 \%$ foetal calf serum. HTC-2 cells were established and cultured as described (Curcio et al, 1994). The human thyroid papillary carcinoma (NPA) cell line was transfected according to the calcium-phosphate transfection protocol (Graham and van der Eb, 1973). Transfected cells were selected in a medium containing G418 $\left(400 \mu \mathrm{g} \mathrm{ml}^{-1}\right)$.

\section{Subtractive library construction and screening}

A subtraction library was constructed enriching for NPA-specific sequences with respect to normal thyroid-specific sequences as described previously (de Nigris et al, 1998). Differential plaque hybridization screening of the NPA(-NT) cDNA library was performed according to a standard procedure (Sambrook et al, 1989). A human melanoma cDNA library constructed in Lambda gt11 vector (Stratagene, La Jolla, CA, USA) was used to isolate full-length cDNA. The library was screened according to protocols provided by the manufacturer.

\section{DNA sequencing and computer analysis}

Positive phages from melanoma cDNA library screening were purified from the phage lysate (Sambrook et al, 1989) and digested with SalI. Inserts were subcloned in pBluescript II SK (Stratagene) and automatically sequenced. The full-length amino acid sequences were compared with sequence of the other sirtuin using 'Blast 2 sequences' from the NCBI Blast website (www.ncbi.nih.gov/gorf/bl.html). The European Molecular Biology Laboratory/GenBank database was searched for known sequences.

\section{RNA extraction and Northern blot analysis}

Total RNA was isolated from cultured cells with the guanidine thiocyanate method, slightly modified (Sambrook et al, 1989). Northern blot analysis, was performed according to standard procedures (Sambrook et al, 1989). A $300 \mathrm{bp}$ cDNA fragment of the SIR-T8 gene was radiolabelled by the random primer method (Feinberg and Vogelstein, 1983). Hybridisations were carried out under stringent conditions according to standard procedures. Hybridisation signals were normalised using a glyceraldehyde-phosphate-dehydrogenase (GAPDH) probe. The filters from normal human and mouse embryo tissues were purchased from Clontech (Palo Alto, CA, USA).

\section{RT - PCR analysis of the SIR-T8 expression in thyroid tumours}

Five micrograms of total RNA digested with RNAse-free DNAse were reverse transcribed using random exanucleotides as primers $(100 \mathrm{mM})$ and 12 units AMV reverse transcriptase (Promega); $0.2 \mu \mathrm{g}$ of cDNA were amplified in $25 \mu \mathrm{l}$ of the reaction mixture containing $0.2 \mathrm{mM}$ dNTPs, $1.5 \mathrm{mM} \mathrm{MgCl}_{2}, 4 \mathrm{mM}$ of each primer, 1 unit of Taq DNA polymerase (Perkin-Elmer) in Taq polymerase buffer. After the first denaturing step at $94^{\circ} \mathrm{C}$ for $2 \mathrm{~min}$, PCR amplification was performed for 30 cycles $\left(94^{\circ} \mathrm{C}\right.$ for $50 \mathrm{~s}, 50^{\circ} \mathrm{C}$ for $50 \mathrm{~s}, 72^{\circ} \mathrm{C}$ for $50 \mathrm{~s}$ ). Sequences of forward and reverse primers used were: $5^{\prime}$-TACCGGATCCAGCGTCTATCCAGACTAC- $3^{\prime}$ and $5^{\prime}$-CTCAGCTGGACGTCCGTATTCGAAGGTA-3'. In addition to primers of the SIR-T8 gene, a set of primers designed to recognize a cDNA for the constitutively expressed enzyme GAPDH was used in each reaction as an internal control for the amount of cDNA tested. The GAPDH specific primers were: forward $5^{\prime}$-ACATGTTCCAATATGATTCC- $3^{\prime}$ and reverse 5'-TGGACTCCACGACGTACTCA-3' corresponding to nucleotides 195-215 and 355-335, respectively (Tokunaga et al, 1987). The amplified products were separated by $1.5 \%$ agarose gel electrophoresis and after Southern blotting, hybridised with a SIR-T8 cDNA probe.

\section{Construction of cDNA expression vector}

The entire cDNA was digested from pBluescript using KpnI/BglII, separated on $1 \%$ agarose gel, purified with a gel extraction kit (Qiagen) and subcloned into the same sites of a mammalian expression vector pFlag CMV (Stratagene). The cDNA was cloned in-frame with a Flag epitope under the transcriptional control of the cytomegalovirus promoter. This vector also carries the gene for G418 resistance.

\section{Immunoblotting and immunocytochemical analysis}

Total protein extracts were prepared as described elsewhere (Cerutti et al, 1996). Western blot was revealed with monoclonal antibodies against the p/Flag epitope at 1 out of 200 dilution (Sigma Chemical Co.). NPA cells were grown on coverslips for $24 \mathrm{~h}$ in DMEM supplemented with $5 \%$ foetal calf serum then transfected; $24 \mathrm{~h}$ after transfection, the cells were briefly rinsed with PBS and fixed with $3 \%\left(\mathrm{w} \mathrm{v}^{-1}\right)$ paraformaldehyde in PBS for $15 \mathrm{~min}$ at room temperature and then permeabilised with $0.2 \%$ Triton for $5 \mathrm{~min}$. The coverslips were incubated with primary antibody in PBS for $1 \mathrm{~h}$ at $37^{\circ} \mathrm{C}$. After three rinses of 5 min each with PBS, the cells were incubated with the second antibody, fluorescein-conjugated antimouse IgG (Amersham Corp.) for $40 \mathrm{~min}$ at $37^{\circ} \mathrm{C}$. Unbound antibody was removed by several $5 \mathrm{~min}$ rinses at room temperature with PBS prior to preparation for fluorescence microscopy.

\section{Chromosome localisation}

A human fibroblast genomic library in the $\lambda$ FIXII vector (Stratagene) was screened at high-stringency conditions using the SIRT8 probe according to a standard procedure (Sambrook et al, 1989). Four phages were isolated. One was further characterised: the insert was excised and sequenced. It shows identity with the human SIR-T8 sequence. This phage was then used for FISH analysis, which was performed as described previously (Veronese et al, 1995; Califano et al, 1998).

\section{RESULTS}

\section{Construction and differential screening of a cDNA subtractive library between NPA cells and normal thyroid cells}

A cDNA subtractive library between the NPA cell line, established from a papillary human thyroid carcinoma, and HTC 2 cells from normal thyroid tissue, was constructed enriching the NPA-specific sequences, as previously described (de Nigris et al, 1998; see Materials and Methods). Subsequently, this library was screened by hybridisation of duplicated filters with cDNAs from poly $(\mathrm{A})^{+}$ mRNAs from NPA and HTC 2 cells, respectively. After three consecutive screenings, we isolated 39 clones that gave rise to a much stronger signal with the NPA probe than with the HTC 2 probe. Six of these clones showed a $100 \%$ identity with a recently isolated gene, designated 'HIP', which encodes a heparan sulphate/heparinbinding protein. Four other clones showed a significant homology with a SIR-like protein family that encodes telomerase-related proteins (Brachman et al, 1995). Northern blot analysis confirmed the presence of a $2.4 \mathrm{~kb}$ band about three-fold stronger in NPA cells than in HTC-2 control cells and thyroid normal tissue $(P<0.001$ vs HTC-2 and N.T.) (Figure 1A).

\section{Isolation and characterisation of a novel gene homologous to SIR family protein and designated 'SIR-T8'}

The isolated cDNA contained an incomplete open reading frame. Therefore, using the cDNA previously isolated as a probe, we 
A
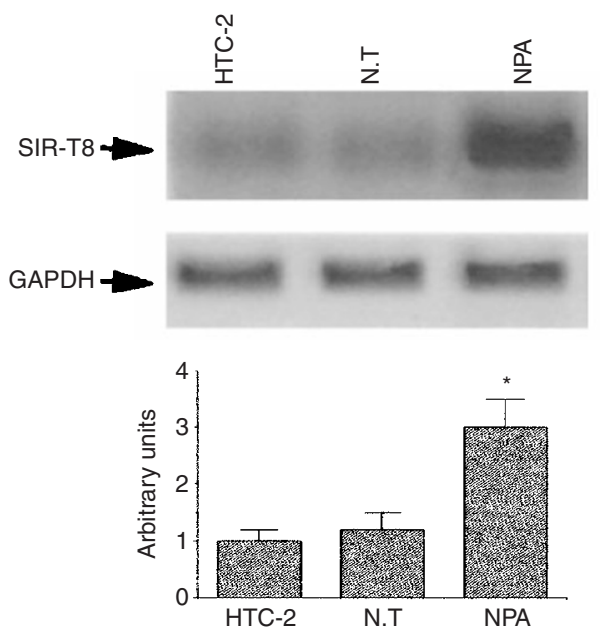

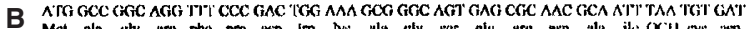

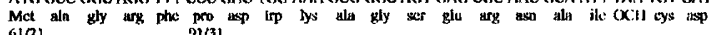

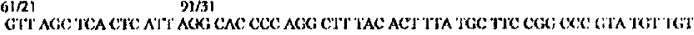

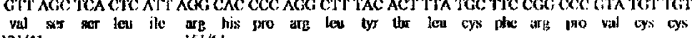

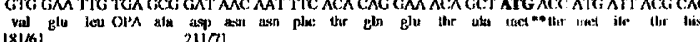

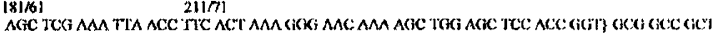

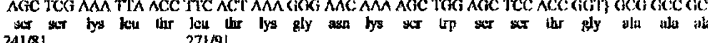

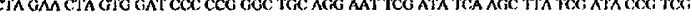

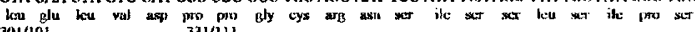
30

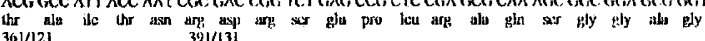

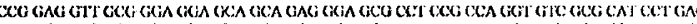

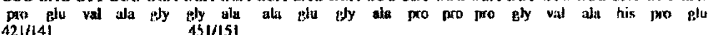

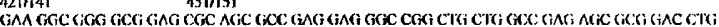

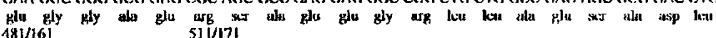

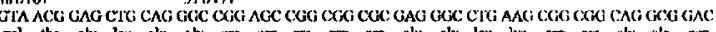

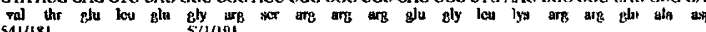

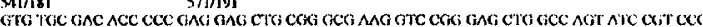

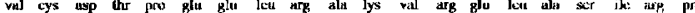

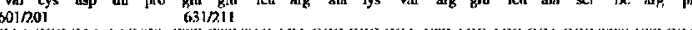

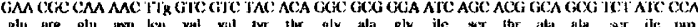

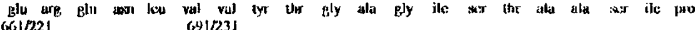

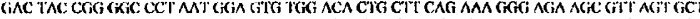

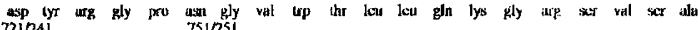
721241 w 751 inst

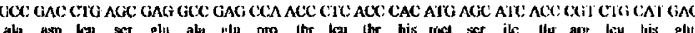

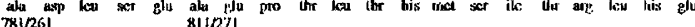

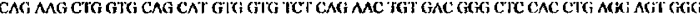

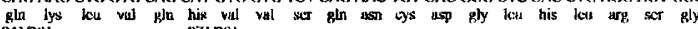

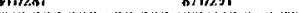

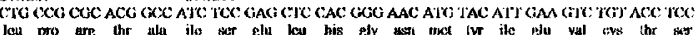

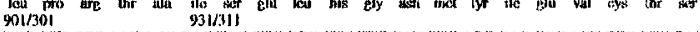

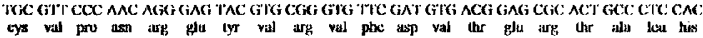

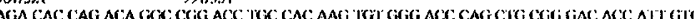

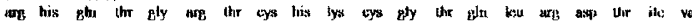

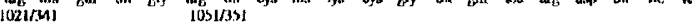

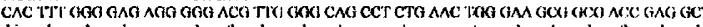

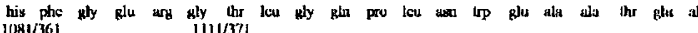

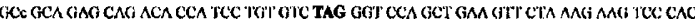
alla alla gilu gin thr pro ser cys val stop $1111 / 381$ 1177/391

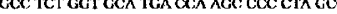
1201/401 1231/411 12614210

12 U1mi

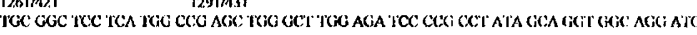

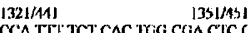

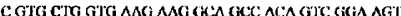

1381/461 $1111 / 4 / 1$

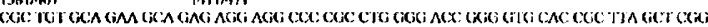

1911/48!

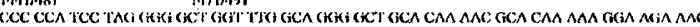

15015301

OPN

ISG1/321 1591/633

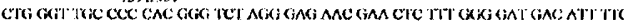

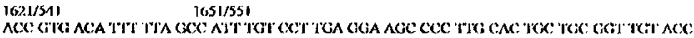

$16 x|/ 50|$

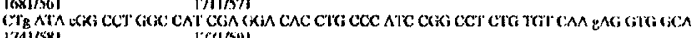

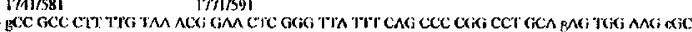

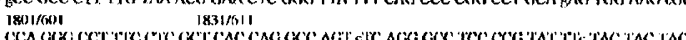

$1861 / 621$

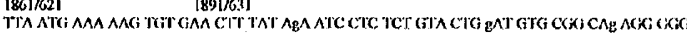

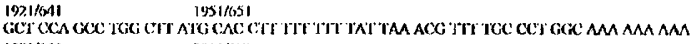

$1981 / 661$ $2011 / 6,11$

C

Sirtuin

$\mathrm{PxxH}$

$H G$

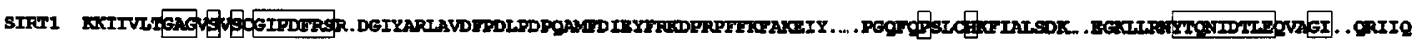

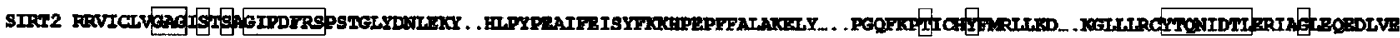

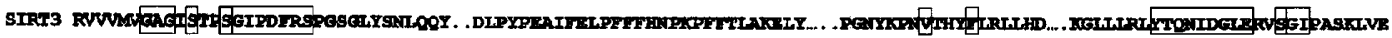

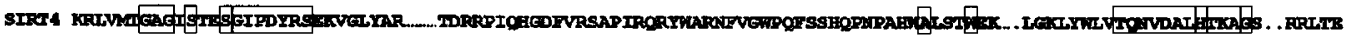

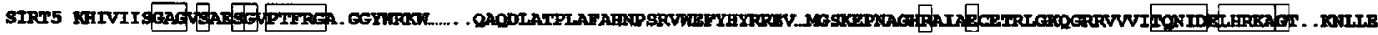

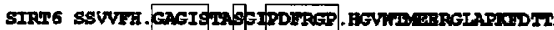

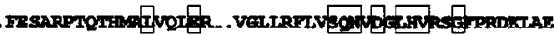

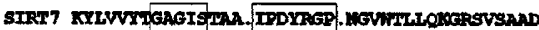

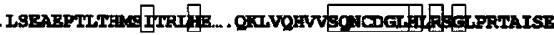

Figure I Northern blot analysis of Sir-T8 expression. (A) Total RNA (5 $\mu$ g per lane) was hybridised with SIR-T8 probe. Lane I: normal thyroid cell line HTC-2, lane 2: Normal tissue; and lane 3: NPA cell line. A GAPDH probe was used as internal control for uniform RNA loading. Lower part: densitometric analysis. Bars present the mean \pm s.d. of the results obtained in three experiments. * $P<0.00$ I vs HTC-2 and normal thyroid tissue (NT). (B) CDNA and amino acid sequences of SIR-T8. Nucleotides are numbered from the beginning of the sequence, and the deduced amino acid sequence is indicated from the beginning of the open reading frame. An in-frame stop codon is indicated in bold. (C) Comparison of the amino acid sequence of SIR-T8 with other known human SIR genes; the conserved domains are boxed. 
screened the melanoma cell library enriched in full-length cDNA. Twelve positive clones were isolated and the inserts were sequenced (Figure 1B). The predicted amino acid sequences show a single open reading frame of $945 \mathrm{bp}$, starting with ATG codon at $162 \mathrm{bp}$ and ending with a stop codon TAG at nucleotides 1110 and 874 of the untranslated $3^{\prime}$ end (Figure 1B). This open reading frame encodes a protein of 315 amino acid residues that has a calculated mass of $39 \mathrm{kDa}$.

A comprehensive search of the EMBL GenBank and the SWISSProtein data base revealed that the predicted amino acid sequence was highly homologous to other known human sirtuin proteins named 'SIR-T' (from 1 to 7 ) and had an $80 \%$ identity to protein SIR-T7 (Frye, 2000). Our gene diverges from SIRT-7 in the 5 ' end, but they have identical or similar amino acid residues scattered throughout the sirtuin domain. In Figure 1C all known human SIRT proteins are aligned and the conserved domain are boxed. There are several amino acidic short motifs conserved within the core domain: GAGISXXXGIPXXR, PXXXH, TQNID, HG; two sets of CXXC that may be a zinc finger domain (Brachman et al, 1995). The HG motif is of interest because a point mutation in this domain causes loss of sirtuin-mediated ADP-ribosylation (Frye, 1999; Tanny et al, 1999).

\section{Analysis of SIR-T8 gene expression in normal and tumoral thyroid cells}

To investigate whether SIR-T8 gene overexpression is a general event in thyroid neoplastic transformation, we analysed its expression in other thyroid carcinoma cell lines of various tumour histotypes by Northern blot. The following cell lines were examined: NIM 1, NPA and TPC-1 from papillary carcinomas; WRO from a follicular carcinoma; and FRO and ARO from anaplastic carcinomas. As shown in Figure 2, SIR-T8 expression was high in all carcinoma cell lines and almost undetectable in normal HTC-2 thyroid cells. SIR-T8 gene expression was particularly abundant in ARO, WRO and FRO cells (five-fold $v$ s HTC-2 $P<0.001$ ) and three-fold higher in NPA than in HTC-2 $P<0.05$ (Figure 2, lower panel).

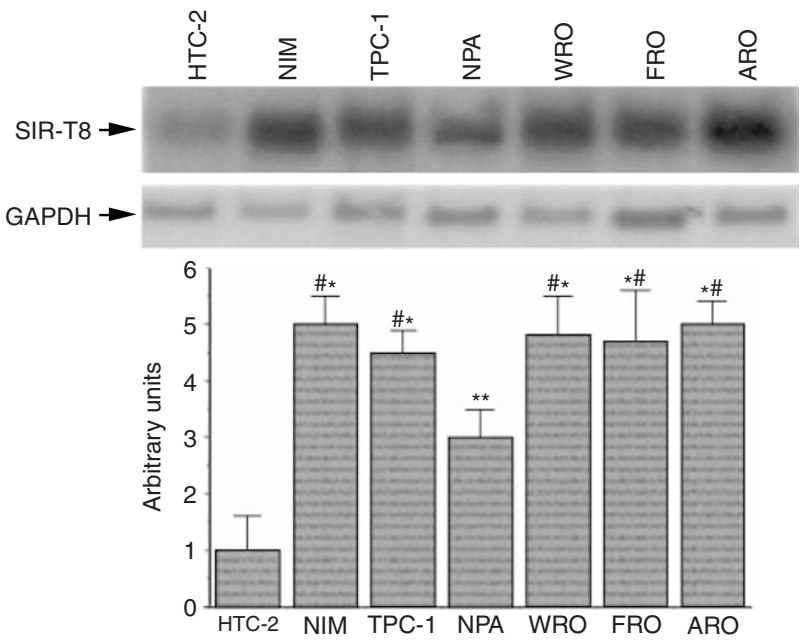

Figure 2 Expression of SIR-T8 in normal and tumoral thyroid cells. Total RNA (5 $\mu$ g per lane) was size-fractionated on denaturing formaldehyde agarose gel, blotted onto nylon filters (hybond-N, Amersham) and probed with SIR-T8 cDNA. RNA was fractioned from the following sources: lane I: normal thyroid primary culture cells; lane 2: NIM cell line; lane 3: TPC-I cell line; lane 4: NPA cell line; lane 5: WRO cell line; lane 6: FRO cell line; lane 7: ARO cell line. A GAPDH probe was used as internal control for uniform RNA loading. Lower panel: densitometric analysis of SIR-T8 expression. Bars present the mean + s.d. of the results obtained in three experiments. $* P<0.0001$ vs HTC2, \#P<0.005 vs NPA and **P $<0.001$ vs HTC2.

Subsequently, we evaluated SIR-T8 gene expression in biopsies from eight papillary carcinomas, three follicular carcinomas, six anaplastic carcinomas and seven adenomas. SIRT-T8 expression was very weak in normal thyroid and in adenomas (Figure 3, upper panel), and abundant in most of the human differentiated papillary and follicular thyroid carcinomas (Figure 3, middle panel) and anaplastic carcinomas (Figure 3, lower panel).

\section{SIR-T8 protein detection and subcellular localisation}

To define the cellular localisation of the SIR-T8 protein, the fulllength cDNA was cloned in a pFlagCMV vector. The Flag epitope identifies the recombinant protein but not the endogenous form of SIRT-8. This construct was transiently transfected in the NPA cell line, which, because of its morphology and shape, makes it easier to locate the recombinant protein. In NPA-transfected cells Western blot revealed a $39 \mathrm{kDa}$ protein that was not detectable in NPA-untransfected cells (Figure 4, upper panel). NPA transfected cells were fixed with paraformaldehyde and stained with anti-Flag antibodies. There was intense cytoplasmic staining in the NPA-transfected cells (Figure 4B). At higher magnification the signal was found to be localised to the perinuclear membrane of NPA cells (Figure 4B).

\section{SIR-T8 gene tissue distribution and chromosomal localisation}

Northern blot analysis of poly(A) ${ }^{+}$mRNAs from different human tissues revealed three mRNA species: 3.5, 2.4 and $1.2 \mathrm{~kb}$ (Figure 5). Gene expression was very weak in stomach and bone marrow. Also spleen, brain, lung and kidney (Figure 5A) expressed low amounts of SIR-T8. These transcripts diverge in their non-coding regions. However, normal thyroid and carcinoma cell lines preferentially express the $2.4 \mathrm{~kb}$ mRNA that drives $39 \mathrm{kDa}$ protein synthesis.

To identify the human chromosomal location of the gene, we screened a human fibroblast genomic library with the SIR-T8 probe. Four phages were isolated. The insert of one of these phages was excised; a $3.0 \mathrm{~kb}$ fragment was subcloned by digestion and sequenced. Because its sequence was identical to the cDNA sequence of SIR-T8, this phage was used for FISH analysis, which showed that the SIR-T8 gene maps to chromosome 17q25-1 (Figure 6).

\section{DISCUSSION}

Differential screening of a subtractive library between a papillary carcinoma cell line (NPA) and normal thyroid cells (HTC-2) led
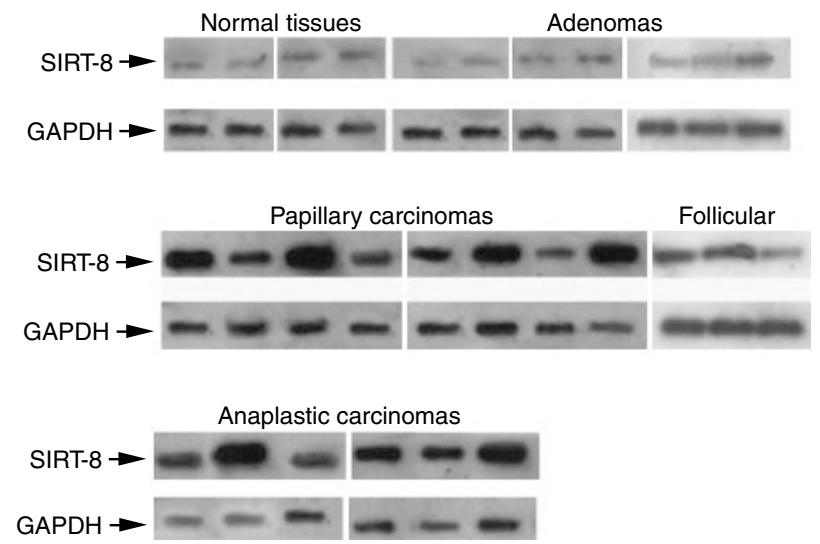

Figure 3 SIR-T8 expression in normal and neoplastic thyroid tissues. RT - PCR analysis of SIR-T8 in normal and neoplastic thyroid tissues. The SIR-T8 mRNA was coamplified with GAPDH as an internal control. RNA sources were divided by pathology as indicated. 
to the isolation of several cDNA clones which were overexpressed in NPA cells. One of the clones corresponded to a novel gene; therefore we isolated the entire cDNA. This cDNA encodes a protein of 315 amino acids with a predicted molecular weight of $39 \mathrm{kDa}$. It is highly homologous to the sirtuin gene family that comprises seven human genes, i.e. SIR-T 1-7. Consequently, we called the gene 'SIR-T8'. Human SIR-T8 had a very high BLASTp score with $85 \%$ identity in the core sirtuin domain to the SIR-T7 protein. The SIR-T8 protein has several short motifs of conserved amino acids within the sirtuin core domain that is common to SIR protein: the GAGISTXXGIPDFR sirtuin core motif, a GVWTL motif at four residues from the $\mathrm{C}$-terminus to the core motif that

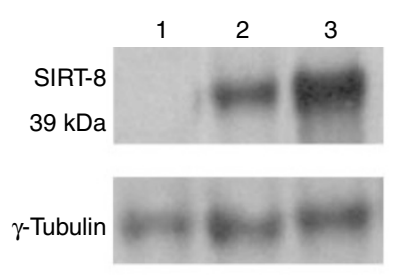

A
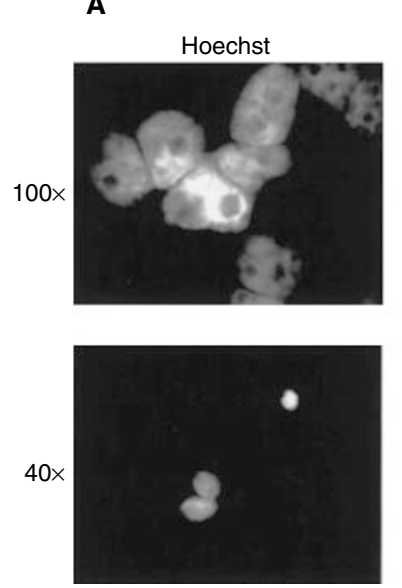

B
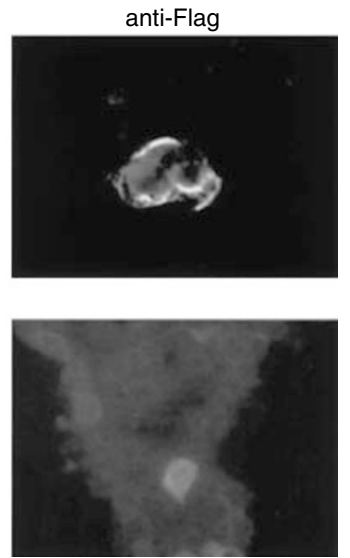

Figure 4 Upper panel: Western blot analysis of protein SIR-T8. Total protein extracts from the NPA cell line transfected and untransfected with p/Flag-SIRT-8 construct were subjected to Western blot analysis with antiFlag monoclonal antibody. Lane 1: untransfected NPA cells; lane 2: NPA cells transfected with the p/Flag-SIRT-8 construct; lane 3: COS cells transfected with the p/Flag-SIRT-8 construct as control. Lower panel: Subcellular localisation of SIR-T8. NPA cells were grown on coverslips for $24 \mathrm{~h}$, transfected with SIR-T8 expression vector and stained with Hoechst $(\mathbf{A})$, or immunostained with anti-Flag antibodies (B) as described. is characteristic of class IV sirtuin, two sets of CXXC that may be zinc finger domains and an HG motif that is strictly conserved in all sirtuin proteins and that is probably involved in ADP ribosylation (Brachman et al, 1995). The enzymatic function of sirtuin is not completely understood. The best characterised of the SIR protein family is SIR-2 from yeast. It mediates histone deacetylation (Tanny et al, 1999) thereby suggesting a coupled reciprocal activation mechanism involving interactions of SIR2 with NAD and the $\mathrm{N}$-acetl-lysine groups of acetylated histones (Imai et al, 2000; Landry et al, 2000).

Here, we report that SIR-T8 codes for a protein that is primarily localised in the cytoplasm under the nuclear membrane. Conversely, most SIR proteins that have telomerase activity are in the nucleolus (Morales et al, 1999). However, our finding is in agreement with the subcellular localisation of other two SIR2related proteins: SIR2L and SIR2p Leishmania major is absent from the nucleus (Zemzoumi et al, 1998).

SIR-T8 was overexpressed in seven carcinoma cell lines but weakly detectable in normal thyroid cell line and tissue. The expression of SIR-T8 was abundant in most of the human thyroid carcinomas analysed. Expression was low or absent in normal thyroid cells tissues and benign adenomas. These results suggest that SIR-T8 induction is a general event in thyroid cell transformation.
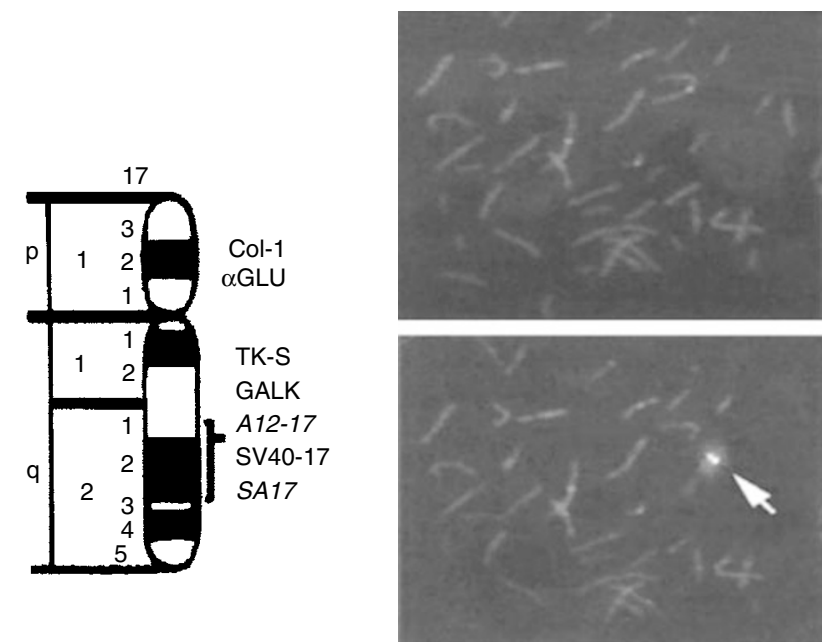

Figure 6 FISH mapping of the SIR-T8 gene to chromosome 17q25.I. Left ideogram of chromosome 17. Right 4',6-diamidino2-phenylindole (top) and corresponding propidium (bottom) FISH analysis of normal lymphocyte metaphase with a phage clone the SIR-T8 gene hybridisation. Note the signal on chromosome 17q25. I.

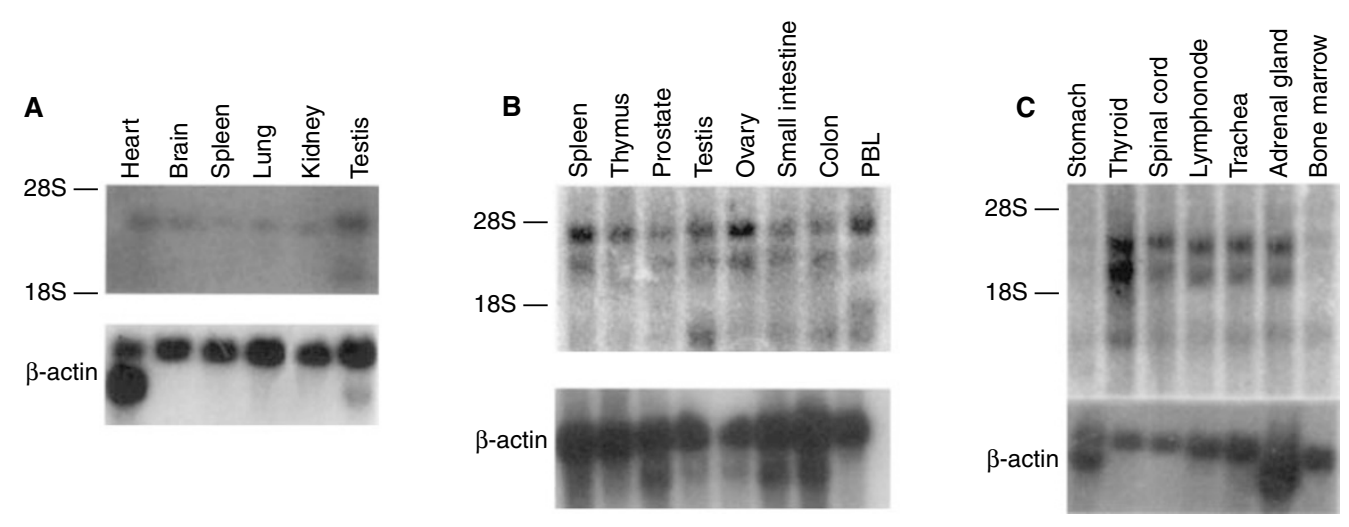

Figure 5 Northern blot analysis of SIR-T8 gene in different normal tissues. SIR-T8 gene expression was analysed in Poly $(A)^{+}$RNAs from various normal tissues as indicated. 
Although the function of protein SIR-T8 needs to be defined, by analogy with the Sir 2 gene, SIR-T8 gene overexpression may play a role in thyroid carcinogenesis. In fact, Sir 2 gene overexpression in yeast causes chromosome instability and a loss in cell viability (Holmes et al, 1997), and interactions between Sir 2 and other SIR genes or histones induce the silenced chromatin state (Ivy et al, 1986; Moretti et al, 1994). Moreover, these proteins modulate the chromatin structure, thereby maintaining patterns of gene expression throughout the development of multicellular organisms, and they are required for telomere maintenance (Orlando and Paro, 1995). Telomeres are specialised structures at the ends of eukaryotic chromosomes. They are ribonucleoproteins that synthesize telomeric DNA on the chromosomal end using a segment of its RNA as template. In most types of human somatic cells the telomeres shorten as with organism age and with repeated passages in culture. The immortal cells that elude crisis are characterised by stable levels of telomerase activity and by stable telomeres. This suggests that telomerase activation can overcome the limitation imposed by telomere length on the lifespan of cell lineages (Counter et al, 1992). In humans, telomerase activity is detectable in germline cells and in certain stem cells, but not detectable in most somatic cell lineages (Harley et al, 1997). It is also detected in most human tumour samples analysed (Counter et al, 1994; Kim et al,
1994) suggesting that telomerase activation may represent an essential step in tumour progression. Moreover, increased expression of the other telomerase proteins correlate with the metastatic phenotype (Sprung et al, 1999).

In conclusion, although the mechanism underlying enhanced SIR-T8 gene expression in thyroid tumours is unknown, the homology of SIR-T8 with the telomerase proteins, and its similarity with telomerase proteins suggests its increased expression might have a role in the process of thyroid carcinogenesis.

\section{ACKNOWLEDGEMENTS}

This work has been supported by grants from AIRC (Progetto Speciale Oncosoppressori), the Progetto Finalizzato 'Biotecnologie' of the CNR, by the Ministero della Ricerca Scientifica e Tecnologica (MURST) project 'Piani di Potenziamento della Rete Scientifica e Tecnologica'. We thank the Associazione Partenopea per la Ricerche Oncologiche (APRO) for its support. Dr Janete Cerutti was a recipient of a fellowship from the Conselho Nacional de Desenvolvimento Cientifico e Tecnologico. F de Nigris was a recipient of a fellowship from APRO. We are grateful to Jean Ann Gilder for revising and editing the manuscript.

\section{REFERENCES}

Brachman CB, Sherman JM, Devine SE, Cameron EE (1995) The Sir2 gene family, conserved from bacteria to humans, functions in silencing, cell cycle progression, and chromosome stability. Gene Dev 9: 2888-2902

Califano D, Monaco C, Santelli G, Giuliano A, Veronese ML, Berlingieri MT, de Franciscis V, Berger N, Trapasso F, Santoro M, Viglietto G, Fusco A (1998) Thymosin $\beta$-10 Gene overexpression correlates with the highly malignant neoplastic phenotype of transformed thyroid cells in vivo and in vitro. Cancer Res 58: $823-828$

Cerutti J, Trapasso F, Battaglia C, Zhang Li, Martelli ML, Berlingieri MT, Fagin J, Santoro M, Fusco A (1996) Blockage of c-MYC protein synthesis in human thyroid carcinoma cell lines reduces their growth in soft agar. Clin Cancer Res 2: 119-126

Chiappetta G, Berlingieri MT, Manfioletti G, Santoro M, Bandiera A, Visconti R, Giancotti V, Fusco A (1995) The expression of the high mobility group HMGI $(\mathrm{Y})$ proteins correlates with the malignant phenotype of human thyroid neoplasms. Oncogene 10: 1307-1314

Chiariotti L, Berlingieri MT, Berger N, De Rose P, Battaglia C, Bruni CB, Fusco A (1993) Increased expression of the negative growth factor, galactoside binding protein gene in transformed thyroid cells and in human thyroid carcinomas. Oncogene 7: 2507-2511

Counter CM, Avilion AA, Le Feuvre CE, Stewart NG, Greider CW, Harley CB, Bacchetti S (1992) Telomere shortening associated with chromosome instability is arrested in immortal cells which express telomerase activity. EMBO J 11: $1921-1929$

Counter CM, Hirte HW, Bacchetti S, Harley CB (1994) Telomerase activity in human ovarian carcinoma. Proc Natl Acad Sci USA 91: 2900-2904

Curcio F, Ambesi-Impiombato FS, Perrella G, Coon HG (1994) Long-term culture and functional characterization of follicular cells from adult normal human thyroids. Proc Natl Acad Sci USA 91: 9004-9008

de Nigris F, Visconti R, Cerrutti J, Califano D, Mineo A, Santoro M, Santelli G, Fusco A (1998) Overexpression of the HIP gene coding for a Heparin/ Heparan sulfate-binding protein in human thyroid carcinomas. Cancer Res 58: $54745-54751$

Feinberg AB, Vogelstein B (1983) A technique for radiolabelling DNA restriction endonuclease fragments to high specific activity. Anal Biochem 132: $613-619$

Frye RA (1999) Characterization of five human cDNAs with homology to the yeast SIR2 gene: Sir2-like proteins (sirtuins) metabolize NAD and may have protein ADP-ribosyltransferase activity. Biochem Biophys Res Commun 260: 273-279

Frye RA (2000) Phylogenetic classification of prokaryotic and eukaryotic Sir2-like proteins. Biochem Biophys Res Commun 273: 793-798

Fusco A, Santoro M (1997) Human thyroid carcinogenesis. Forum 7.2: $214-$ 229
Graham FL, van der Eb AJ (1973) A new technique for the assay of infectivity of human adenovirus 5 DNA. Virology 52: 456-467

Harley CB, Kim NW, Prowse KR, Weinrich SL, Hirsch KS, West MD, Bacchetti S, Hirte HW, Counter CM, Greider CW (1997) Telomerase, cell immortality and cancer. Cold Spring Harb.. Symp Quant Biol 59: 307-315

Hedinger C, Williams ED, Sobin LH (1989) The WHO histological classification of thyroid tumors a commentary on the second edition. Cancer 63: $908-911$

Holmes SG, Rose AB, Steuerle K, Saez E, Sayegh S, Lee YM, Broach JR (1997) Hyperactivation of the silencing proteins, Sir $2 p$ and Sir3p, causes chromosome loss. Genetics 145: 605-614

Imai SI, Armstrong CM, Kaeberlein M, Guarente L (2000) Transcriptional silencing and longevity protein Sir2 is an NAD-dependent histone deacetylase. Nature 403: 795-800

Ivy JM, Klar AJS, Hicks JB (1986) Cloning and characterization of four SIR genes of Saccharomyces cerevisiae. Mol Cell Biol 6: 688-702

Kaeberlein M, McVey M, Guarente L (1999) The SIR2/3/4 complex and SIR2 alone promote longevity in Saccharomyces cerevisiae by two different mechanisms. Gene Dev 13: 2570-2580

Kim NW, Piatyszek MA, Prowse KR, Harley CB, West MD, Ho PLC, Coviello MG, Wright WE, Weinrich SL, Shay JW (1994) Specific association of human telomerase activity with immortal cells and cancer. Science 266: $2011-2015$

Kroll TG, Sarraf P, Pecciarini L, Chen CJ, Mueller E, Spiegelman BM, Fletcher JA (2000) Pax8-PPARgammal fusion in oncogene human thyroid carcinoma. Science 289: 1357-1360

Landry J, Sutton A, Tafrov ST, Heller RC, Stebbins J, Pillus L, Stermglanz R (2000) The silencing protein SIR2 and its homologs are NAD-dependent protein deacetylases. Proc Natl Acad Sci USA 97: 5807-5811

Morales CP, Holt SE, Ouelette M, Kaur KJ, Yan Y, Wilson KS, White MA, Wright WE, Shay JW (1999) Absence of cancer-associated changes in human fibroblast immortalized with telomerase. Nature Genetics 21: $115-118$

Moretti P, Freeman K, Coodly L, Shore D (1994) Evidence that a complex of SIR proteins interact with the silencer and telomere-binding protein RAP1. Gene Dev 8: $2257-2269$

Orlando V, Paro R (1995) Chromatin multiprotein complexes involved in the maintenance of transcription patterns. Curr Opin Cell Biol 5: 174-179

Pierotti MA, Bongarzone I, Borello MG, Greco A, Pilotti S, Sozzi G (1996) Cytogenetics and molecular genetics of carcinomas arising from thyroid epithelial follicular cells. Genes Chrom Cancer 16: 1-14

Sambrook J, Fritsch EF, Maniatis T (1989) Molecular Cloning: A Laboratory Manual. Cold Spring Harbor, NY: Cold Spring Harbor, Laboratory 
Shay JW, Bacchetti S (1997) A survey of telomerase activity in human cancer. Eur J Cancer 5: 787-791

Sherman JM, Stone EM, Freeman-Cook LL, Brachman CB, Boeke JD, Pilus L (1999) The conserved core of human SIR homologue functions in yeast silencing. Mol Biol Cell 10: 3045-3059

Sprung NG, Sabatier L, Murnane JP (1999) Telomere dynamics in human cancer cells. Exp Cell Res 247: 29-37

Tanny JC, Dowd GJ, Huang J, Hilz H, Moazed D (1999) An enzymatic activity in the yeast Sir2 protein that is essential for gene silencing. Cell 99: $735-745$

Tokunaga K, Nakamura Y, Sakataka K, Fujimari K, Ohkuba M, Sawada K, Sakiyama S (1987) Enhanced expression of glyceraldehyde-3-phosphate dehydrogenase gene in human lung cancer. Cancer Res 21: 5616-5619
Veronese ML, Ohta M, Finan J, Nowell PC, Croce CM (1995) Detection of myc translocation in lymphoma cells by fluorescence in situ hybridization with yeast artificial chromosomes. Blood 85: 2132-2138

Visconti R, Cerutti J, Battista S, Fedele M, Trapasso F, Zeki K, Miano MP, de Nigris F, Casalino L, Curcio F, Santoro M, Fusco A (1997) Expression of the neoplastic phenotype by human thyroid carcinoma cell lines requires NFkB p65 protein expression. Oncogene 15: 1987-1994

Zemzoumi K, Sereno D, Francois C, Guilvard E, Lemestre JL, Ouaissi A (1998) Leishmania major: cell type dependent distribution of a $43 \mathrm{kDa}$ antigen related to silent information regulatory-2 protein family. Biol Cell 90: $239-245$ 